\title{
Angiotensin II Use in Refractory Multisystem Shock: A Case Report
}

\author{
Mohamed Ahmed ${ }^{1}$, Saba Habis ${ }^{2}$, Ahmed Mahmoud ${ }^{1}$, Cedric Rutland ${ }^{3}$, Rasha Saeed ${ }^{4}$
}

1. Surgery, Riverside Community Hospital / Envision Healthcare, Riverside, USA 2. Internal Medicine, Riverside Community Hospital / Hospital Corporation of America, Riverside, USA 3. Internal Medicine, Riverside Community Hospital, Riverside, USA 4. Surgery, Riverside Community Hospital / University of California, Riverside, USA

Corresponding author: Mohamed Ahmed, maamsmd@yahoo.com

\begin{abstract}
Distributive (vasodilatory) shock is common in patients admitted to the intensive care unit (ICU). Treating distributive shock presents a challenge, especially if a patient is tachyphylactic to commonly used vasopressors. This case report illustrates the use of a newly approved vasopressor in a patient with vasodilatory shock resulting from a motor vehicle injury. A 56-year-old man was brought to our emergency department (ED) hemodynamically unstable requiring aggressive resuscitation. The results of his evaluation were consistent with multisystem trauma for which he required intubation on arrival, and he received multiple units of blood and blood product via transfusion. The patient's condition declined despite receiving multiple vasopressors in the ICU. A few days after admission, the patient developed ischemic bowel requiring surgical resection. While his chance of survival was believed to be dismal, the use of angiotensin II (ATII) as a last resort proved to be helpful.
\end{abstract}

Categories: Other, Trauma

Keywords: vasopressors, trauma, vasodilatory shock, angiotensin ii

\section{Introduction}

Distributive (vasodilatory) shock is frequently encountered in intensive care unit (ICU) patients, and treating distributive shock can be difficult and puzzling, especially if tachyphylaxis to the commonly used vasopressors becomes an issue. Vasopressors are used in patients who remain hypotensive after adequate fluid resuscitation. There has been a paradigm shift in avoiding the use of dopamine in favor of norepinephrine augmented by vasopressin (an antidiuretic hormone) to minimize the dose of norepinephrine. In cases where a refractory shock is associated with poor cardiac output, dobutamine has been found to be useful. Responsiveness to commonly used drugs can decrease over time as a result of tachyphylaxis. This case illustrates the use of a newly approved vasopressor in vasodilatory shock.

Received 11/07/2018

Review began 11/14/2018 Review ended 11/28/2018 Published 11/30/2018

\section{() Copyright 2018}

Ahmed et al. This is an open access article distributed under the terms of the Creative Commons Attribution License CC-BY 3.0., which permits unrestricted use, distribution, and reproduction in any medium, provided the original author and source are credited.

\section{Case Presentation}

A 56-year-old male pedestrian was brought to our emergency department (ED) after being struck by a car at high speed resulting in an unstable pelvic fracture, massive retroperitoneal bleeding, pulmonary contusion, and traumatic rupture of the diaphragm which was not evident at the time of admission. He was admitted to our Level II trauma center ICU after initial resuscitation in the ED. Renal failure progressed rapidly due to rhabdomyolysis. His early post-injury course was complicated by refractory shock requiring high doses of vasopressors, hypoxic hypercapnia respiratory failure on ventilation support, ischemic colitis, septic shock, cardiogenic shock that required cardioversion on three different occasions, acute renal failure requiring continuous renal replacement therapy, and shocked liver. The patient required multiple visits to the operating room with initial resection of the terminal ileum and right colon, repair of the diaphragmatic hernia, chest tube insertion followed by washout, ileostomy, feeding gastro-jejunostomy tube, and biologic mesh closure.

Despite receiving high-dose norepinephrine, vasopressin, and epinephrine, the patient's condition continued to deteriorate with a mean arterial pressure $<60 \mathrm{mmHg}$. Angiotensin II (ATII) was given as an infusion starting with $5 \mathrm{ng} / \mathrm{kg} /$ minute increments. The max maintenance dose of $15 \mathrm{ng} / \mathrm{kg} /$ minute was achieved in three hours reaching our target blood pressure (BP) for the first 24 hours, and was tapered to 10 $\mathrm{ng} / \mathrm{kg} /$ minute during the next 12 hours and to $5 \mathrm{ng} / \mathrm{kg} /$ minutes during the last 12 hours. ATII was completed with no side effects. The patient's condition dramatically improved, and he was weaned off of vasopressors within three days of the ATII use. He survived his injuries and was referred to acute rehabilitation.

\section{Discussion}

Shock (hypovolemic, obstructive, distributive, and cardiogenic) is a state of tissue and cellular hypoxia due to decreased delivery, increased consumption or inadequate utilization of oxygen. Distributive shock (also known as vasodilatory shock) is the result of severe peripheral vasodilation. Vasodilatory shock is multifactorial and characterized by peripheral vasodilation and preserved or increased cardiac output, high 
mortality, and limited therapeutic options [1-2]. Vasoconstriction can be achieved by stimulating adrenergic (alpha, beta 1,2) and dopaminergic receptors, the use of calcium sensitizers, and stimulation of angiotensin (AT) receptors (AT1,2). ATII is an endogenous peptide hormone produced in the pulmonary endothelium. In respiratory failure, pulmonary capillary angiotensin-converting enzyme activity will decrease, impairing ATII production.

ATII has a vasoconstrictive effect on the venous and arterial smooth muscle [3], and exerts its effects by binding to specific AT receptors that vary based on the type of cell membrane (e.g., AT-1, AT-2, AT-4 and Mas receptors). The major physiological effects are mediated by AT-1 receptors located in the kidneys, vascular smooth muscle, lung, heart, brain, adrenals, pituitary gland, and liver and relate to maintenance of hemodynamic stability and fluid and electrolyte regulation [2]. During sepsis, down-regulation of both AT-1 and AT-2 receptors will occur, inhibiting catecholamine release by the adrenal medulla and attenuating the responsiveness of $\mathrm{BP}$ and aldosterone formation [4].

Sepsis also leads to an imbalance between vascular mediators. Vasodilating factors (e.g., nitric oxide, tumor necrosis factor- $\alpha$, histamine, kinins, and prostaglandins) are released, whereas the vasoconstrictor response to ATII and catecholamines might decrease [5-6]. Refractory septic shock is associated with impaired microvascular flow and reduced capillary density at sub pressor levels [7]. Other factors can further influence the development of microcirculatory dysfunction, including low tissue oxygen pressure, production of hypoxia-inducible factors, redox, and ATII potential alterations [6]. The encouraging findings of improved macro-circulatory hemodynamics and decreased catecholamine requirements after ATII administration are offset by evidence of microcirculatory dysfunction that could result from high levels of ATII [8]. Intravenous ATII is associated with increased BP in patients with cardiogenic, distributive, and unclassified shock. Further, a role may exist for ATII in restoring circulation in cases of cardiac arrest [9-10].

When septic shock and respiratory failure coexist, failure of the lungs to convert ATI to ATII could be a factor leading to refractory septic shock, and patients might benefit from exogenous ATII [11]. As part of the reninangiotensin-aldosterone system (RAAS) in which the kidneys are the driving organ, ATII increases efferent renal arteriolar resistance to a level greater than the afferent renal arteriolar resistance, serving to increase the intra glomerular pressure, decrease overall renal blood flow, and augment the filtration fraction [12]. Exogenous ATII prevents renal ischemia through RAAS and improves renal function without decreasing intrarenal oxygenation during septic shock [13]. ATII plays an important role in liver function as well. The liver fails to produce angiotensinogen during refractory shock leading to a potential need for (and benefit of) exogenous ATII [14]. Patients with a higher severity of illness and relative deficiency of intrinsic ATII who received exogenous ATII had improved mortality and infrequent adverse reactions-evidence that ATII is safe for use in patients with vasodilatory shock. ATII can be an effective novel agent that increases BP in refractory multisystem shock and, potentially, overall survival in patients who do not respond to high doses of conventional vasopressors [2-3,15-16].

\section{Conclusions}

The use of ATII had recently shown to be a possible adjunct to other frequently used vasopressors. Synthetic human ATII does not appear to have a contraindication for its use thus far; however, arterial and venous thromboembolic events have been reported. While further trials are warranted to confirm the benefits of ATII, intensivists should consider the use of ATII in hypotensive patients in distributive shock.

\section{Additional Information \\ Disclosures}

Human subjects: Consent was obtained by all participants in this study. Conflicts of interest: In compliance with the ICMJE uniform disclosure form, all authors declare the following: Payment/services info: All authors have declared that no financial support was received from any organization for the submitted work. Financial relationships: All authors have declared that they have no financial relationships at present or within the previous three years with any organizations that might have an interest in the submitted work. Other relationships: All authors have declared that there are no other relationships or activities that could appear to have influenced the submitted work.

\section{References}

1. Wakefield BJ, Sacha GL, Khanna AK J: Vasodilatory shock in the ICU and the role of angiotensin II . Curr Opin Crit Care. 2018, 24:277-285. 10.1097/MCC.0000000000000517

2. Busse LW, McCurdy MT, Ali O: The effect of angiotensin II on blood pressure in patients with circulatory shock: a structured review of the literature. Crit Care. 2017, 21:324. 10.1186/s13054-017-1896-6

3. Chow JH, Galvagno SM Jr, Tanaka KA: When all else fails: novel use of angiotensin II for vasodilatory shock . A \& A Pract. 2018, 11:175-180. 10.1213/XAA.0000000000000775

4. Vincent JL, De Backer D: Circulatory Shock. N Engl J Med. 2013, 369:1726-1734. 10.1056/NEJMra1208943

5. Bissell BD, Browder K, McKenzie M: A blast from the past: revival of angiotensin II for vasodilatory shock . Ann Pharm. 2018, 52:920-927. 10.1177/1060028018767899

6. Antonucci E, Fiaccadori E, Donadello K: Myocardial depression in sepsis: from pathogenesis to clinical 


\section{Cureus}

manifestations and treatment. J Crit Care. 2014, 29:500-11. 10.1016/j.jcrc.2014.03.028

7. Haber E: Recent developments in pathophysiologic studies of the renin-angiotensin system . N Engl J Med. 1969, 280:148-55. 10.1056/NEJM196901162800308

8. Sakr Y, Dubois MJ, De Backer D: Persistent microcirculatory alterations are associated with organ failure and death in patients with septic shock. Crit Care Med. 2004, 32:1825-31.

10.1097/01.CCM.0000138558.16257.3F

9. Khanna A, English SW, Wang XS: Angiotensin II for the treatment of vasodilatory shock. N Engl J Med. 2017, 377:419-430. 10.1056/NEJMoa1704154

10. De Backer D, Biston P, Devriendt J: Comparison of dopamine and norepinephrine in the treatment of shock . N Engl J Med. 2010, 362:779-89. 10.1056/NEJMoa0907118

11. Imai Y, Kuba K, Rao S: Angiotensin-converting enzyme 2 protects from severe acute lung failure . Nature. 2005, 436:112-6. 10.1038/nature03712

12. Denton KM, Anderson WP, Sinniah R: Effects of angiotensin II on regional afferent and efferent arteriole dimensions and the glomerular pole. Reg Int and Comp Phys. 2000, 279:R629-R638.

10.1152/ajpregu.2000.279.2.R629

13. Tumlin JA, Murugan R, Deane AM: Outcomes in patients with vasodilatory shock and renal replacement therapy treated with intravenous angiotensin II. Crit Care Med. 2018, 46:949-957.

10.1097/CCM.0000000000003092

14. Wilkinson SP, Williams R: Renin-angiotensin-aldosterone system in cirrhosis . Gut. 1980, 21:545-554. 10.1136/gut.21.6.545

15. Jentzer JC, Vallabhajosyula S, Khanna AK: Management of refractory vasodilatory shock. Chest. 2018, 2:416-426. 10.1016/j.chest.2017.12.021

16. Antonucci E, Gleeson PJ, Annoni F, et al.: Angiotensin II in refractory septic shock. Shock. 2017, 47:560-66. 10.1097/SHK.0000000000000807 